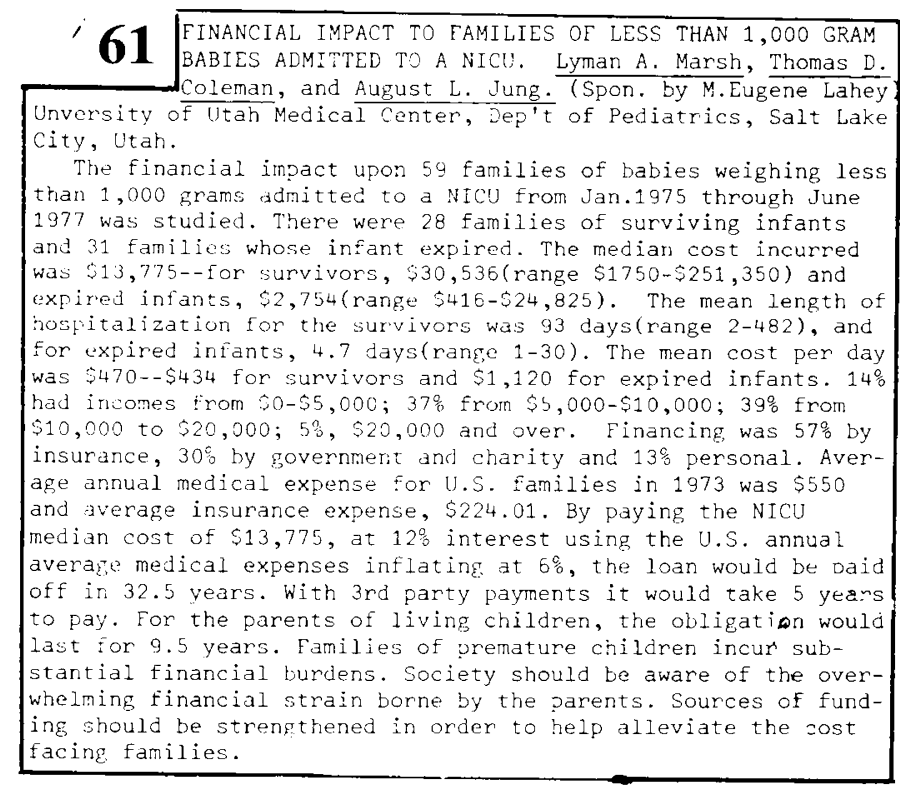

62

MINIMAL BRAIN DYSFUNCTION SYNDROME IN CHILDHOOD: ATE OUTCOME IN RELATION TO INITIAL PRESENTATION AND NITIAL DIAGNOSTIC CATEGORIES. Doris H. MiIman,

Downstate Medical Center, Department of Pediatrics, Brooklyn, Ny
73 patients, diagnosed in childhood as having minimal brain dysfunction, were followed into adolescence and early adult life (average duration 12.4 years). Delayed speech (74\%), delayed motor development $(41 \%)$, and tantrums $(60 \%)$ did not show any significant correlation with outcome. Early school problems (84\%) immaturity $(62 \%)$, social problems $(56 \%)$, fearfulness and anxiety (55\%), and anti-social behavior in childhood (18\%) all correlated in various specific ways with psychiatric symptoms (e.g. anxiety, obsessiveness, tics) and with psychopathological

tive, (personality disorders, including schizoid, passive-aggres ive, inadequate and anti-social). Initially patients were end neurological findings into developmental lag( $\left.3 \delta^{2} \%\right)$ and organic and neurological findings into developmental lag( $38 \%)$ and orga
prain syndrome $(62 \%)$. At follow-up $58 \%$ continued to manifest organic brain syndrome. Learning disability, present initially in $92 \%$, persisted in $67 \%$. Schizoid personality traits, present initially in $32 \%$, were present finally in $44 \%$. The original diagnosis of developmental lag strongly correlated with the findings on follow up of passive-aggressive personality, anti-social personality, and depressive symptoms. The initial diagnosis of of organic brain syndrome, inadequate personality, schizoid individuals ( $7 \%$ ) were free of psychiatric disorder at follow-up

\section{NEUROPSYCHOLOGICAL DYSFUNCTION IN CHILDREN WITH} "SILENT" LEAD EXPOSURE. Herbert L. Heedleman, Charles Gunnoe, Alan Leviton. Henry Peresie. Spon. by :iarren Grupe. Harvard Medical School, Children's Hosnital ledical Center, Dept. of Psychiatry, Boston. Lead exposure in a cohort of "normal" first and second grade children ( $N=1411$ ) was determined by dentine lead analysis in shed primary teeth. Children in the highest and lowest ranges for lead were then exanined blindly wit: a comnrehensive neuronsychologic battery. Thirty covariates known to af fect measured outcome (SES, race, birtineight, etc.) were scaled. iiigh leac children did not differ sirnificantly on any control variables from low lead chiluren, but tended to be slightly olcler and of slightly lower SES. Analysis of covariance, controlling for age and SES was performed on 83 low and 33 high lead subjects. Children with low birthweight, history of lead intoxication, or head injury vere excluded from the analvsis. Significant differences favoring low lead children were found on 13 of the 37 outcome measures (2-tailed test, ANACOVA. $p$ values indicated in parentheses). VISC-R: rull scale (.017), Verbal (.009), subtests: Infornation (.018), Similarities (.047), Vocabulary (.016), Jicit Span (.009), Block Desian (.009). Other tests which showed significant differences vere: Seashore Rhythm (.003), "at! Achievement (.008), Readin Comprehension (.014), Sentence Renetition (.003), Token Test of Lanquace $(.01)$ and Piaqetian Conservation (.007). Eight other tests showed differences not reaciing significance, $(\mathrm{P}<.05)$, but favoring the low lead groun.

Setzer, Sally Whitley, Deborah Gustin, Harriet Cloud, Susan John of Ped. and Center for Dev. and Learning Disorders, Birmingham. $26 / 31(84 \%)$ surviving NICU infants with birthwelghts $4950 \mathrm{~g}$.bo 4/74-1/77 were evaluated by an interdisciplinary team including pediatricians(2), psychologist, audiologist, optometrist, developmentalist, social worker, nutritionist and R.N. The study began in $1 / 76$ with evaluations performed at ages $6,12,18,24$ and 36 mos. Mean age at last evaluation was 18 mos. (range 6-38 mos.). Population characteristics included mean birth weight $889 \mathrm{~g}$. (range 650940 g.); mean gestational age 28.4 wks. (range 24-33 wks., 7/26 small for gestational age); male:female 10:16; inborn:outborn $5: 21$; and Black:White:Other $13: 12: 1$. Results were corrected for gestational age.

Significant major morbidity was found in $9 / 26(34.6 \%)$ including stage $\mathrm{V}$ retrolental fibroplasia (RLF)(1); developmental delay (7 with DQ 670$)$; cerebral palsy(6); acquired hydrocephalus(2); exereme failure to thrive (FTT) (3). $6 / 9(67 \%)$ affected infants had pultiple major handicaps. $11 / 17$ infants without major handicaps had one or more minor disabilities including stage II RLF(1); re current lower mild conductive hearing loss( 8 ); mild FTT(2); visual disorders (4) prrested hydrocephalus(3) and scoliosis(1). Although longitudinal followup may alter some of the results reported, it appears that survival without major morbidity is occurring in $65 \%$ of surviving infants with birthweights $<950 \mathrm{~g}$.

65 PSYCHOLOGICAL COSTS OF SURVIVING CHILDHOOD CANCER John E. O'Malley, G.P. Koocher, D.J. Foster, J.L. GoInstitute, Children's Hospital Medical Center, Harvard Medical School, Boston, Massachusetts.

Psychosocial interviews of 100 long-term survivors of pediatric cancer and their families reveal a significant level of resid ual psychological sequelae. The patients studied were diagnosed as having a malignancy at least five years prior to intervew, and were off treatment and in disease-free remission for at least one year. The median interval since diagnosis was 13 years and the patients' present ages range from 6 to 36 years. Findings demonstrate a significantly poorer degree of psychological adjustment by cancer patients in comparison with a small comparable group of control patients with prior non-life-threatening illneses. Well-adjusted pediatric cancer survivors and their famliles fend to use denial effectively to avoid anxiety, while poorly adjusted patients remain anxious and uncertain about the future. Employment and insurance discrimination are a significant problem, even for patients who have been disease-free for many years. patients who contract malignancies of infancy have a better proghosis for long-term psychological adjustment than do those with onset of malignancies in middle childhood or adolescence. A very high percentage of patients expressed the wish that psychological support services had been available to them at the time of active treatment. Most participants also gave strong support to the

heed for open and honest communication about the seriousness of

66 DEVELOPMENT OF CRITICALLY-ILL. INFANTS GREATER THAN 2500 GRAMS. Michael B. Resnick, Robert M. Nelson Donald V. Ejtzman, Ernest F. Beale, Richard L. Bucciarel1 $i$, Edmund A. Egan, Jon W. Nagel, University of Florida College of Medicine, Shands Teaching Hospital, Department of Pediatrics, Gainesville.

There is limited developmental outcome data available on near term infants requiring intensive care. To assess the impact on larger infants requiring such care, a $20 \%$ random sample of infants $>2500$ grams discharged from the University of Florida Regional Neonatal Intens ive Care Center (RNICC) between 1975-1976 were evaluated at 21 months post conceptual age. The Bayley Scales of Infant Development's mental and physical development quotients (MDQ/PDQ) and physical and neurological exams were the outcome assessment measures administered utilizing a blind exper imental design. Mean gestational age was 39 weeks and mean hospital stay was 7 days. No statistical differences were found by race or sex of the infants. Those infants who were transferred to the RNICC had MDQ and PDQ significantly lower than those born inhouse. $B W \quad$ MDQ PDQ NEUROLOGICAL BIRTHWEIGHT (BW) $\frac{N}{\bar{X}}$ 的

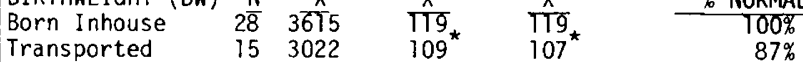
\begin{tabular}{llllll} 
TOTAL GROUP & 43 & 3560 & 116 & 115 & $87 \%$ \\
\hline
\end{tabular} TOTAL GROUP
$\begin{aligned} & \star_{p}<.05 \\ & \text { Since only sick infants in this weight group are transported, }\end{aligned}$ Since only sick infants in this weight group are transported,
the lower MDQ and PDQ may be just a reflection of the initial the lower MDQ and PDQ may be just a reflection of the initial
disease. 